\title{
La necesidad de un mapa para la provincia. La institucionalización del conocimiento cartográfico y catastral durante el siglo XIX en la Provincia de Buenos Aires
}

\author{
The need of a map for the province. Institutionalization of cartographical and \\ cadastral knowledge during the nineteenth century in the Province of Buenos \\ Aires
}

\author{
Melisa Pesoa \\ melisa.pesoa@upc.edu \\ Universitat Politècnica de Catalunya - Departamento \\ de Urbanismo y Ordenación del Territorio - Grup de \\ Receca en Urbanisme (GRU), España
}

Recepción: 23 Julio 2020

Aprobación: 16 Septiembre 2020

Publicación: 02 Noviembre 2020

Cita sugerida: Pesoa, M. (2020). La necesidad de un mapa para la provincia. La institucionalización del conocimiento cartográfico y catastral durante el siglo XIX en la Provincia de Buenos Aires. Geograficando, 16(2), e083. https:// doi.org/10.24215/2346898Xe083
Resumen: Este artículo busca poner en valor la actividad del Departamento Topográfico como productor y recopilador del saber territorial durante el siglo XIX en la provincia de Buenos Aires. Buscamos demostrar que, desde su establecimiento en 1824 y con diferentes nombres, el Departamento pasa de ser una institución central para la conformación del Estado, concentrando múltiples funciones, a ser una sección técnica dentro una estructura más amplia como fue el Ministerio de Obras Públicas de la Provincia de Buenos Aires. Mediante el análisis de esta repartición, buscamos demostrar la íntima relación que existía entre la producción de mapas topográficos y catastro durante el siglo XIX, cuando los medios y las técnicas disponibles obligaron a la unión de esfuerzos. Ello fue posible gracias a la estandarización de los trabajos, a la redacción de instrucciones, en suma, a una normalización de las prácticas que tiene su origen en el estado rivadaviano y se prolonga durante todo el siglo.

Palabras clave: Provincia de Buenos Aires, Cartografía, Catastro, Departamento Topográfico.

Abstract: This article intends to highlight the activity of the Department of Topography as producer and compiler of territorial knowledge during the nineteenth century.We seek to demonstrate that, since its establishment in 1824 and under different names, the Department shifted from a central institution for building the State, concentrating multiple functions, to a technical section within a greater and more complex structure: The Ministry of Public Works of the Province of Buenos Aires. Through the analysis of this office, we seek to prove the close connection between the production of topographic maps and cadastre during the nineteenth century, when the available means and techniques forced this union of efforts. This was possible thanks to work standardization and instruction writing; in short, a normalization of practices that originated in the Rivadavian State and lasted throughout the century.

Keywords: Province of Buenos Aires, Cartography, Cadastre, Department of Topography. 


\section{INTRODUCCIÓN}

El presente artículo busca poner en valor la actividad cartográfica y catastral llevada a cabo por los técnicos bonaerenses en el siglo XIX como una herramienta de consolidación del Estado. El Departamento Topográfico de Buenos Aires fue la primera institución catastral de América Latina y desarrolló el primer catastro con efectos civiles en la región, convirtiéndose en una institución modelo para otras regiones del país y del continente. ${ }^{1}$ Nos interesa, por lo tanto, indagar acerca de su rol en la producción de las primeras cartografías realizadas desde el Estado provincial en el periodo independiente, los procedimientos para elaborarlas y el encuadre de la institución a lo largo de los casi cien primeros años de su existencia.

La reflexión que presentamos se enmarca en el cruce de dos líneas de investigación. La primera tiene que ver con explorar los "saberes de Estado", es decir los "saberes expertos y operativos demandados por, y a la vez constitutivos del, Estado moderno" (Plotkin y Zimmermann, 2012, p. 10). Desde el siglo XVIII los Estados comenzaron a necesitar sistemáticamente el conocimiento proporcionado por diversas ciencias y saberes técnicos para mejorar la administración. Al mismo tiempo, estos saberes necesitaron al Estado para consolidarse e institucionalizarse. Bohoslavsky y Soprano (2010) proponen estudiar el Estado "desde dentro" y de manera descentralizada, evitando la mirada desde las ciudades capitales y las agencias del poder ejecutivo nacional. Asimismo, plantean no sólo enfatizar los aciertos, sino ofrecer una representación de los lugares a los que al Estado le costó llegar o simplemente no llegó.

Está claro que la constitución del Estado argentino tras la independencia fue un proceso lento y complejo, muy lejos de una evolución lineal (Oszlak, 1982; Chiaramonte, 1997). El Estado bonaerense, inicialmente entendido como el Gobierno de Buenos Aires, encargado de administrar el territorio bajo su jurisdicción, se construyó con reparticiones creadas aún antes que en el Estado Nacional. En este marco, el Departamento Topográfico cobra una relevancia singular, pues es una de las primeras agencias estatales surgidas tras la Independencia, y nos preguntamos qué rol jugaron los saberes técnicos de este Departamento en la construcción del Estado provincial y cómo fue su proceso de institucionalización.

La segunda línea explora específicamente el rol de los saberes técnicos en el dominio del territorio, en línea con estudios como los de Kain y Baigent (1992) -quienes analizan el rol del catastro en la construcción del Estado-, Craib (2013) - que estudia el rol que las prácticas científicas y técnicas relacionadas con la cartografía tienen en la construcción social del espacio, con foco en el caso mexicano-, y Schlögel (2007)--que reivindica la lectura espacial como elemento esencial para construir la historia, con especial énfasis en la producción cartográfica-.Nos interesa retroceder hasta el momento en que empezaron a implantarse los saberes técnicos en el Río de La Plata y cómo se desarrollaron hasta institucionalizarse como parte del Estado provincial, para poner de relevancia la combinación entre catastro y cartografía que tuvo lugar a lo largo del siglo XIX con el objetivo de construir un mapa de la provincia.

La actuación del Departamento Topográfico ha sido estudiada por varios autores desde diferentes miradas. Francisco Esteban (1962) nos aporta una cronología histórica con la transcripción de los documentos legales esenciales para comprender los progresivos cambios sucedidos a nivel institucional a lo largo de más de un siglo. Martínez Sierra (1975) realiza un pormenorizado estudio de la producción cartográfica para la región pampeana desde tiempos coloniales hasta la década de 1880. Más recientemente, encontramos los textos de D’Agostino (2007 y 2015), Canedo (2013 y 2014) o Pesoa (2017), que indagan en las condiciones sociales que hicieron posible la emergencia y desarrollo de esta actividad, relacionándola con temas de propiedad de la tierra o con la fundación de poblaciones. Nicolau (2005) y Asúa (2010) ponen el foco en las relaciones 
entre técnica y ciencia para la primera mitad del siglo XIX, donde el DT y sus integrantes tienen un papel relevante. Para el periodo posterior, a partir de la creación del DI y luego del Ministerio de Obras Públicas de la Provincia (MOPBA), destacamos los trabajos de D’Agostino y Banzato (2015) y el de Fernández (2019).

Aliata y Loyola (2005), entre otros autores, analizan las relaciones entre los funcionarios del DT y las Comisiones de Solares, encargadas de distribuir los terrenos dentro de los ejidos, comenzando a "espacializar", de alguna manera, la actividad de estos profesionales. En esta "espacialización" de los estudios relacionados con el DT, sin duda un gran avance lo constituye la obra de Garavaglia y Gautreau (2011).

Este artículo busca poner en valor la actividad del Departamento Topográfico como productor y recopilador del saber territorial durante el siglo XIX. No obstante, buscamos evidenciar que, desde su establecimiento en 1824 y con diferentes nombres, el Departamento pasó de ser una institución central para la conformación del Estado provincial, concentrando múltiples funciones, a ser una sección técnica dentro una estructura mucho mayor (el MOPBA) dedicada exclusivamente a producir cartografía. Para estudiar este cambio, el hilo conductor que proponemos para este texto es la razón que da origen al establecimiento del Departamento Topográfico: la necesidad de construir un mapa de la provincia de Buenos Aires. Esta valiosa información cartográfica permitiría trazar estrategias de administración, colonización, defensa, conectividad, entre otras. En suma, se trataba de dibujar el territorio sobre el cual se pretendía gobernar, una característica propia del Estado moderno.

A lo largo de este texto, veremos que la necesidad de ese mapa coloca al Departamento Topográfico en una posición de centralidad en la organización del Estado en la década de 1820. No obstante, la construcción progresiva de una cartografía cada vez más certera, y la consolidación de la ocupación del territorio hacia finales del siglo XIX, traslada a esta agencia a una posición periférica dentro de la organización estatal. Nuevas necesidades dieron lugar a nuevas agencias, un cambio que irá en consonancia con otros más amplios relacionados con políticas, discursos, demandas sociales y técnicas de modernización, entre otros factores.

En este sentido, pretendemos dar cuenta de la profesionalización de la construcción del catastro y ciertas producciones cartográficas, así como encuadrar esta producción en la construcción del Estado provincial. Mediante el análisis de esta repartición, buscamos, por un lado, demostrar la íntima relación que existía entre la producción de mapas topográficos y el catastro a principios del siglo XIX, cuando los medios y las técnicas disponibles obligaron a la unión de esfuerzos. Ello fue posible gracias a la estandarización de los trabajos, a la redacción de instrucciones, en suma, a una normalización de las prácticas que tiene su origen en el Estado rivadaviano y se prolonga durante todo el siglo XIX. Dichas prácticas sirvieron de instrumento para la consolidación de los saberes técnicos que tenían a su cargo. Por otro lado, buscamos evidenciar la delimitación más clara de funciones, propia de la especialización de las diferentes agencias estatales, que comienza a acentuarse a partir del último cuarto del siglo XIX.

Si bien otros autores han estudiado esta institución en etapas particulares, en este texto se pretende abarcar un periodo más amplio, que va desde el establecimiento de la Comisión Topográfica en 1824 hasta la creación de la sección de Geodesia del Ministerio de Obras Públicas de la Provincia de Buenos Aires (MOPBA) en 1913. Esta visión de larga duración nos permite poner en perspectiva los cambios institucionales que atravesó esta repartición a lo largo del siglo XIX. La elección del final del periodo de estudio pone de manifiesto que,en las primeras décadas del siglo XX,la geodesia pasa a ser una cuestión específica y de menor envergadura dentro de las nuevas problemáticas que debe afrontar la provincia. Estos nuevos requerimientos estaban más ligados a la cohesión territorial y social de una provincia que necesitaba mayor integración una vez establecidos los nuevos núcleos de población, tal como indica Fernández (2019). Por lo tanto, serían indispensables conocimientos específicos sobre ferrocarriles, vialidad, o incluso aviación, entre otros temas.

Trabajar un periodo extenso nos permite observar continuidades y cambios en las políticas públicas relacionadas con el conocimiento del territorio y su proyecto. Para ello examinaremos diversas fuentes primarias -tales como mensuras, cartografía, correspondencia, publicaciones oficiales el Estado provincialasí como fuentes secundarias que han trabajado sobre el período de estudio y la temática planteada. 
Este artículo se compone de tres apartados que pretenden verificar cada uno de los objetivos planteados. El primero se centra en demostrar la necesidad de una institución de este tipo para el nuevo país que se empezaba a construir. En el segundo se exploran los vaivenes institucionales, las continuidades y rupturas, por las que atraviesa esta repartición a lo largo de los casi cien años que abarca nuestro periodo de estudio. En el tercer apartado se verifican la metodología de trabajo del Departamento, acorde a las necesidades y limitaciones del contexto, y algunos de los resultados cartográficos generales. Finalmente, se esbozan las principales conclusiones y se plantean algunas líneas abiertas de investigación.

\section{UNA INSTITUCIÓN NECESARIA}

Durante la segunda década del siglo XIX, y principalmente a partir de la Revolución de Mayo y de la Independencia, se volvió cada vez más acuciante para el gobierno de la Provincia de Buenos Aires la necesidad de tener datos fidedignos sobre el territorio que se pretende colonizar y poner a producir. La pampa era una vasta extensión de tierra, de la cual sólo una pequeña parte era conocida y estaba cartografiada: su conocimiento más o menos certero abarcaba la zona al Norte del Río Salado y algún camino específico de penetración al interior. La falta de personal y el poco interés que hasta el momento revestía la colonización de la llanura pampeana, entre otros factores, habían retrasado durante muchísimo tiempo los trabajos de levantamiento, en tanto que los existentes no se apoyaban sobre bases firmes ni existía uniformidad en los procedimientos.

Los esfuerzos comenzaron a ser sistemáticos a partir de la implantación de las Reformas Borbónicas en el Río de la Plata en el último cuarto del siglo XVIII, en consonancia con lo que sucedía en el resto del Imperio, tanto en la península como en América. Estaba claro que el conocimiento del territorio era una condición indispensable para su administración, puesta en producción y colonización. Para gobernar, se necesitaban estadísticas, medidas, inventarios, entre otros elementos que posibilitarían al Estado ser un conjunto institucional que funcionara racionalmente.

Los funcionarios borbónicos que visitaron el Río de La Plata entre finales del XVIII y las dos primeras décadas del XIX dejaron constancia en sus memorias de que, para implementar las estrategias de población que proponían como método para afianzar la colonización, era indispensable conocer el territorio y, por ende, encarar trabajos de exploración y levantamiento, así como construir una cartografía certera. Los primeros trabajos sistemáticos de reconocimiento del territorio interior de Buenos Aires fueron las expediciones encargadas al coronel Pedro Andrés García, quien advertía sobre la necesidad de un mapa donde se registrará el territorio correspondiente a cada partido, los límites de las tierras, los propietarios, los pueblos y ejidos junto con los accidentes geográficos de la región y datos estadísticos de los diferentes territorios (Informe del año 1811, en Gelman, 1997, p. 66). En el Diario de viaje a las Salinas, también de 1811, García reclamaba urgentemente la mensura de las tierras:

Las mensuras generales de la campaña deben partir, a mi juicio, desde la plaza misma de la Victoria, siguiendo, para evitar perjuicios, el orden establecido por D. Juan de Garay. Para esta operación deben elegirse sujetos que, además de los conocimientos científicos, estén adornados de una integridad a toda prueba. Ellos han de ser infatigables, hasta que perfeccionen un plano topográfico que señale exactamente los territorios de cada partido, sus límites y haciendas en él comprendidas: sus pueblos e iglesias, sus pastos comunes, aguadas y egidos, con una razón estadística, la más prolija.

Esta operación bien desempeñada aclarará luego las respectivas propiedades, pondrá al gobierno en el estado de conocer cuáles son las tierras realengas, qué extensión ocupa su dueño y a qué destina su propiedad. Éste será el documento solemne que asegure el patrimonio de nuestra común familia: sobre este plano es que V.E. va a plantear la grandeza y poder de la República. (Informe del 26 de noviembre de 1811 y fragmentos del Diario del viaje a Salinas, en Gelman, 1997, p. 81).

El informe de García proponía a la tierra como tema central de discusión. Al final del ciclo colonial, la campaña estaba caracterizada por una producción agrícola importante y una producción ganadera diversificada, con el predominio de pequeñas y medianas explotaciones familiares, donde los grandes 
hacendados constituían un sector modesto en proporción al resto (Gelman, 1997, p. 15). Los problemas sobre las condiciones de tenencia de la tierra se arrastraban desde hacía al menos 200 años y, salvo las iniciativas mencionadas anteriormente, a partir de la creación del Virreinato del Río de La Plata, en 1810 el territorio de Buenos Aires no sobrepasaba la tradicional barrera del Río Salado.

Sin embargo, a partir de 1810,comenzó a evidenciarse la intención de expandir el territorio rural, donde confluían diferentes intereses en un escenario no exento de conflictos, a partir de la apertura del comercio y las posibilidades de ampliar la actividad productiva en el interior. En medio de las luchas políticas por la organización nacional, Buenos Aires decidió explotar sus dos riquezas: el puerto y una extensa llanura con suelo de excelente calidad, cuya puesta en producción, requería -comparada con otras actividades-, un esfuerzo bastante menor.

Asimismo, tras la crisis de 1820, se gestó una razón más para aventurarse al interior de la pampa. Durante la gestión de Rivadavia como ministro de gobierno de Martín Rodríguez -a la sazón Gobernador de la provincia de Buenos Aires y a cargo del Poder Ejecutivo Nacional-, el Estado no contaba con fondos para realizar obras públicas y por ello se contrató un préstamo con la casa inglesa Baring Brothers \& Co. $^{2}$ Como garantía de ese préstamo se hipotecaron tierras e inmuebles de propiedad estatal que, una vez hipotecados, no podían venderse. Pese a ello, era necesario sacarle rédito y por eso se decidió entregarlas bajo el régimen de enfiteusis.

La importancia dada a la tierra durante la gestión rivadaviana tenía que ver además con la mirada de la Ilustración a finales del siglo XVIII, a través de la fisiocracia, vista desde un contexto americano, sobre la importancia de la tierra como elemento productivo central de la sociedad -y de la que también nos hablaba García en su informe antes citado-, y por eso su correcto manejo eraesencial para llevar a buen puerto la ocupación del territorio bonaerense. La tierra se convirtió así en un elemento clave para conseguir la tan ansiada "civilización".

Ya desde 1812, en un decreto de su propia autoría, ${ }^{3}$ Rivadavia expresaba la necesidad de convocar a un grupo de gente especializada para levantar un plano topográfico de todo el territorio de la provincia para poder conocerlo, establecer poblaciones y dar productividad al suelo. Este plano, decía:

...dará una idea de la estadística de este precioso suelo, desconocido hasta ahora de sus mismos habitadores. A este fin ha nombrado una comisión de sujetos inteligentes. Tiene por objeto esta medida repartir gratuitamente a los hijos del país, suertes de estancias proporcionadas, y chacras para la siembra de granos, bajo un sistema político que asegure el establecimiento de poblaciones y la felicidad de tantas familias patricias... (R.O., año 1812).

La idea de encarar un levantamiento sistemático del territorio de la provincia formó parte de una serie de estrategias destinada a fomentar la organización del incipiente Estado provincial en torno al paradigma de regularidad -enunciado por Aliata (2006)-, puesto que la regularidad militar, política y física debían estar relacionadas:

...el orden regular se presenta como un instrumento... que crea una rutina política predecible. Esta rutina puede instrumentarse sólo a partir del cumplimiento de los reglamentos, los códigos, las acciones repetidas y visibles (...) La otra condición de la regularidad es su forzosa ausencia de complejidad formal. La complejidad se parece necesariamente al desorden (Aliata, 2006). ${ }^{4}$

Pese a que tardaron mucho tiempo en verse reflejadas sobre el terreno, algunas modernizaciones institucionales incipientes estuvieron presentes desde finales del siglo XVIII. No obstante, fue a partir de la gestión de Rivadavia cuando las reformas y proyectos de ordenamiento institucional comenzaron a materializarse. ${ }^{5}$

Por otra parte, la emergencia de la actividad ganadera como fuente de riqueza, reclamaba también la necesidad de sacar provecho de la enorme cantidad de tierra disponible. Para ello se habían había impulsado varias medidas desde la Revolución de Mayo atendiendo a diversas solicitudes de los sectores interesados. Algunas de estas se registran en El telégrafo Mercantil, o en La Abeja argentina, y se refieren a la necesidad de 
estructurar un sistema administrativo y técnico sobre las tierras disponibles, tanto para su distribución como para la recaudación de impuestos.

Para ello se necesitaba un buen número de técnicos con los conocimientos necesarios, que escaseaban en la zona en aquellos años. Sin embargo, Rivadavia había pasado 5 años en Inglaterra y Francia, donde había tenido amplio contacto con las ideas ilustradas, de tal forma que, para concretar su reforma administrativa, invitó a algunos profesionales como el español Felipe Senillosa, los franceses Pierre Benoit, Próspero Catelín, Charles Henri Pellegrini o José Pons, junto con el inglés James Bevans o el italiano Carlo Zucchi. ${ }^{6}$ Ellos serían la base para conformar los cuerpos técnicos durante su gestión.

El germen de la labor topográfica en la provincia lo constituirá el ya mencionado decreto del 4 de septiembre de 1812, sancionado por el Gobierno de la Provincia de Buenos Aires en acuerdo con el Ayuntamiento de la ciudad de Buenos Aires, que ordena la creación de una Comisión Especial para elaborar el plano de la provincia con el objeto de repartir las tierras: "con inspección de la naturaleza de los diferentes terrenos que comprende, y que dará una idea de la estadística de este precioso suelo, desconocido hasta de sus mismos habitadores". Con este decreto comenzó la organización de una agencia estatal dedicada al saber territorial, que se concretará en la década de 1820 mediante el establecimiento de una serie de departamentos encargados de las obras públicas a nivel de la ciudad y su hinterland -el Departamento de Ingenieros Arquitectos (DIA), el Departamento de Policía, el de Ingenieros Hidráulicos (DIH) ${ }^{7}$ - y la Comisión Topográfica (CT), más tarde llamada Departamento Topográfico (DT). Nos centraremos en los que tuvieron mayores competencias sobre el conocimiento del territorio.

El 2 de octubre de 1821 se creó, por un lado, el cargo de Ingeniero Arquitecto de la ciudad y, por el otro, el DIA, ${ }^{8}$ presidido por el Ing. Arq. Próspero Catelín. Este Departamento tenía a su cargo el control de la edificación en la ciudad, el poder de policía sanitaria, la traza de calles y caminos, obras hidráulicas y otros servicios urbanos.

El primer encargo que se le hizo al DIA fue formar una colección topográfica y estadística de la provincia. Posteriormente, en 1823 se le encarga levantar el plano de todos los pueblos de la campaña en jurisdicción de la provincia, empezando por San Nicolás de los Arroyos. Esto demuestra que, inicialmente, se esperaba que este departamento se encargara del tema de tierras, y específicamente de levantar el mapa de la provincia, además de la obra pública. Sin embargo, como veremos, este encargo será demasiado grande para una institución totalmente nueva y con escasos recursos.

En 1823 se creó un registro de tierras, ${ }^{9}$ a cargo del Ministerio de Gobierno, con el objetivo de llevar todas las escrituras, que incluyen la mensura del terreno. $\mathrm{Al}$ año siguiente, en 1824, se dictaron una serie de reglas para ejecutar estas mensuras ${ }^{10} \mathrm{y}$, posteriormente, se creó la CT. ${ }^{11}$ Esta Comisión quedó encargada de realizar el plano topográfico de la provincia y de aprobar todas las mensuras que se realizaran en territorio bonaerense, entre otras tareas que tenían que ver mayormente con el desempeño de los agrimensores. ${ }^{12}$

Dos años más tarde, en 1826, ${ }^{13}$ se creó el Departamento General de Topografía y Estadística (más tarde llamado DT), en reemplazo de la CT. ${ }^{14}$ Este cambio, de Comisión a Departamento, implica un aumento de rango, lo que resulta en una mayor asignación de recursos y de personal. Recordemos que, en el decreto de establecimiento de la CT de 1824, no quedaban determinados los rangos de los tres principales integrantes ni de los dos auxiliares, así como tampoco las asignaciones monetarias que percibirían. En cambio, en el decreto de establecimiento del DT, sí que se especificó el rango que tendrán los diferentes integrantes y el sueldo a percibir. De esta manera el DT quedaría constituido por un jefe (Vicente López y Planes), un ingeniero primero (Felipe Senillosa), un ingeniero segundo (Avelino Díaz) y un ingeniero secretario (Agustín Ibáñez de Luca), además de tres oficiales, en orden de jerarquía (1. Juan Saubidet, $2 .^{\circ}$ Manuel Eguía y $3 .^{\circ}$ Juan María Gutiérrez), dos escribientes, cuatro delineadores y un portero.

Este cambio conlleva, además, mayor jerarquía y autonomía, y una comunicación directa con el Ministerio de Gobierno, según reza mismo decreto: "El Departamento se comunicará oficialmente con todas las 
autoridades de la República, dependerá solamente de la Presidencia Nacional, y estará a las inmediatas órdenes del Ministerio de Gobierno."Esta comunicación directa con el Ministerio de Gobierno podría haber favorecido una resolución más rápida de los asuntos. ${ }^{15}$

Un par de años más tarde, teniendo en cuenta que las funciones del DIA las ejecutaba mayormente el Ingeniero de la Provincia, Juan Pons, y que muchos de sus trabajos los ejecutaba el DT, el gobierno provincial decidió suprimir el DIA el 14 de febrero de 1828, y determinó que sus trabajos fueran ejecutados por Pons. Asimismo, en vista de que las obras encomendadas al DIH (puerto y aguas corrientes) no se realizarían, el Gobierno decidió suspender esta repartición el 7 de diciembre de 1822 y que todo su instrumental y producción pasase al DT.

Vemos así cómo, al finalizar el periodo rivadaviano, el único organismo que sobrevive es el Departamento Topográfico, concentrando casi todas las funciones de las otras reparticiones. Esta posición de centralidad que adquiere el DT tiene una gran implicancia a nivel político, pues demuestra que el problema de conocer, medir y catastrar el territorio es una preocupación central del gobierno. Esto es así porque la tierra era un valor esencial en aquel momento, dado que se había transformado en mercancía y en el futuro económico de la región.

Por lo tanto, se produce un cambio en la mirada sobre cómo debe estar documentada la tierra, que implica la configuración de una agencia estatal dedicada específicamente aeste fin. Este organismo forma parte así de una serie de reformas burocráticas establecidas en la década del veinte que, basándose en las reformas burocráticas y administrativas que habían sido instituidas durante la época napoleónica en Francia, buscan generar una elite administrativa técnica especializada, que concentre un saber que será esencial para la construcción del nuevo Estado.

\section{Continuidades y RUPTURAS EN LAS PRÁCTICAS DEL DT}

El análisis de su trayectoria desde 1824 hasta 1913 nos permite examinar las continuidades y rupturas del DT con respecto a su proyecto fundacional, así como entrever una concentración cada vez más marcada de funciones técnicas en manos del Estado.

En 1820 no existía prácticamente ninguna organización estatal en la provincia ${ }^{16}$ a nivel de agencias o reparticiones encargadas de cuestiones administrativas y/o técnicas y, como hemos adelantado, el gobierno disponía de escasa información cartográfica. Por lo tanto, para cumplir con el objetivo de construir el mapa de la provincia, se escogieron a los profesionales que más conocimiento tenían del tema en aquel momento. Las tres primeras autoridades de la Comisión fueron Felipe Senillosa (ingeniero militar español), ${ }^{17}$ Vicente López y Planes (jurisconsulto y, a la sazón, editor del registro estadístico), y Avelino Díaz (catedrático de físico-matemáticas), a las que luego se suman Martiniano Chilavert como primer oficial, Juan Saubidet como segundo escribiente y Agustín Ibáñez de Luca como oficial meritorio. 
FIGURA 1

Organigrama de la posición del DT dentro de la organización del gobierno entre 1820 y 1885

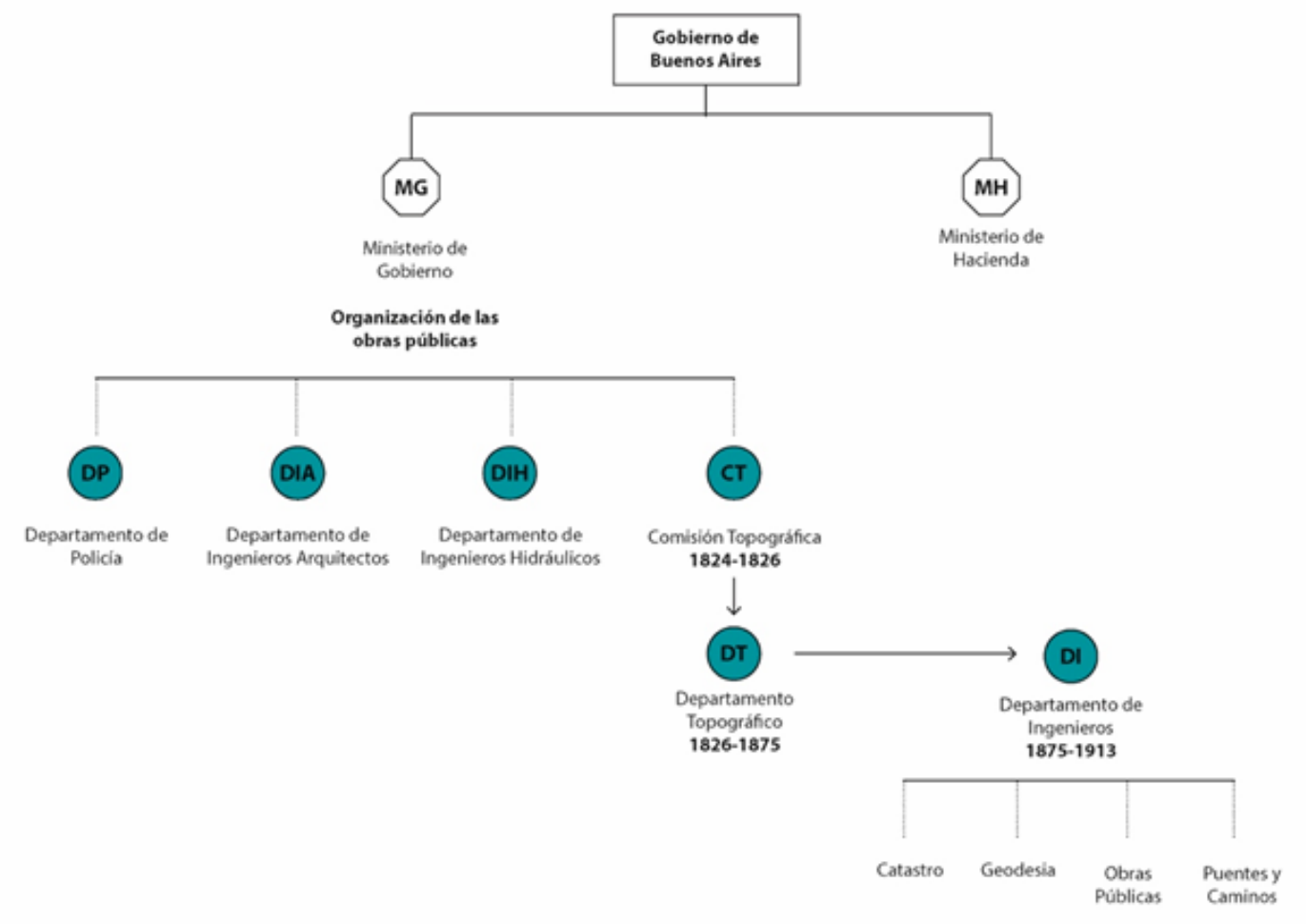

Fuente: elaboración propia.

La CT tenía como atribuciones reunir los datos para confeccionar el mapa de la provincia de Buenos Aires, aprobar las mensuras de terrenos de particulares o del Estado, acreditar mediante un examen a los agentes encargados de efectuar las mediciones y reglamentar el ejercicio de la profesión. Se trataba de una amplia y variada cantidad de funciones, muy difíciles de sostener con escaso personal y presupuestos. Incluso más, si consideramos que en ese decreto figuraban ciertas competencias relacionadas con la obra pública. ${ }^{18}$

Cuando en 1826 la CT pasó a ser DT, asumió además funciones estadísticas (como reunir datos estadísticos de todas las provincias y publicarlos anualmente) y aumentó su labor topográfica: se encargaba de oficiar de tribunal en litigios de mensuras, resolver todo lo relativo a límites, tanto en propiedad pública como privada, regular la actividad de la agrimensura -examen, patente y control-, la conservación de los mojones, declinación de plazas, de calles y caminos, y traza de los pueblos.

Durante la primera época, el DT reunió a los miembros más cualificados en temas de cartografía y geodesia, y además acreditó a una buena cantidad de agrimensores para ejercer la profesión. ${ }^{19}$ Por otra parte, y a pesar de la incertidumbre con la que había comenzado sus trabajos, el DT logró presentar una carta general de la Provincia basada en mensuras existentes y viajes.

La importancia de esta carta radica en que fue el primer trabajo encarado por el Estado durante el periodo independiente y que es el fruto directo de varios relevamiento in situ del terreno. Lo que se pretendía desterrar era la práctica usual de combinar datos obtenidos de relevamientos con datos supuestos por los compiladores que completaban la cartografía. En otras palabras, se buscaba obtener una cartografía basada totalmente en datos científicos objetivos.

Por otra parte, aunque se trataba de un croquis, el DT indicaba que constituía una base para proceder en varios trabajos del DT y del Ministerio. La pretensión era, por lo tanto, trazar un meridiano de referencia en la ciudad de Buenos Aires y una línea perpendicular para, a partir de esos ejes, trazar líneas guía que permitieran colocar mojones para obtener una malla abstracta a la cual referenciar todas las mediciones futuras. 
FIGURA 2

Carta Geográfica de la Provincia de Buenos Aires (1829)

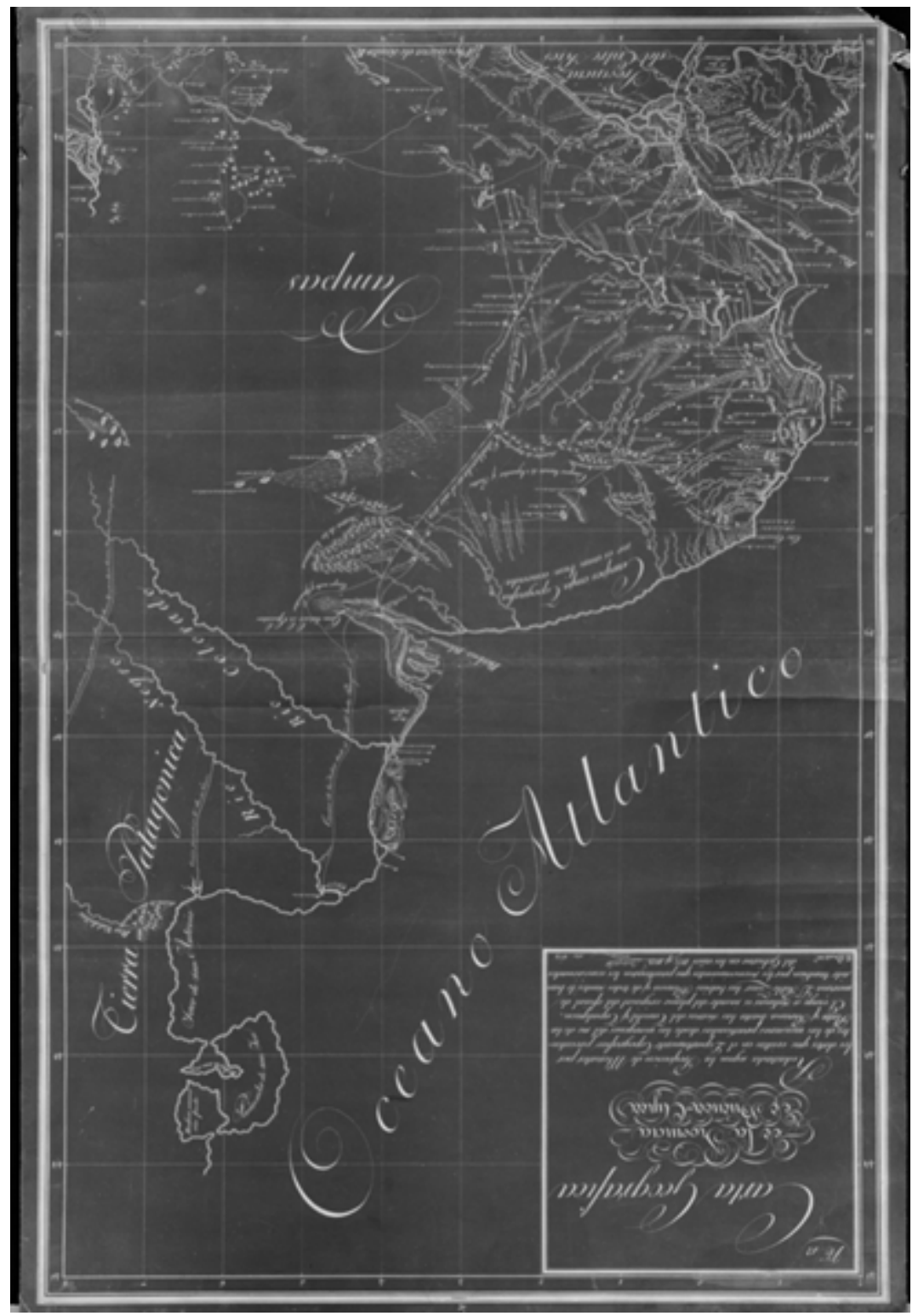

Redactada según la proyección de Mercator en base a los datos que existen en el Departamento Topográfico procedentes de las mensuras practicadas desde las márgenes del Río de la Plata y Paraná hasta las Sierras de Tandil y Tapalquén. El viaje a Salinas se extrajo del plano original del oficial de marina Don Pablo Zizur, los datos sobre la zona de Bahía Blanca y Bahía de todos los Santos provenía de los reconocimientos que practicaron los comisionados del Gobierno en los años 1822 y 1823 Fuente: AGN, Mapoteca, II-105

Tras la caída de Rivadavia en 1827 la situación del DT se tornó más complicada, tanto por falta de presupuesto como por inestabilidad política producto de los conflictos civiles. Durante el gobierno de Juan Manuel de Rosas (1829-1932 y 1935-1852), el DT contaba con escaso personal e instrumental para efectuar los trabajos. Las razones de ello podrían ser varias. En primer lugar, la gran inestabilidad del personal producida por diversos motivos, entre los que destaca la ideología política: por ejemplo, Avelino Díaz murió de enfermedad en 1831 y Octavio Mossotti renunció en 1835; por motivos políticos Gutiérrez fue apartado del cargo hacia 1836 y se instaló en Uruguay, José María Manso huyó a Brasil y José María Romero emigró a Perú. 
Por otra parte, analizando la producción total de mensuras para nuestro periodo de estudio (que retomaremos más adelante) podemos observar que, si bien es cierto que la producción del DT decae notablemente durante este período con respecto al anterior, es posible identificar una producción mayor entre los años 1835 y 1839, incluso superior a la de años anteriores, pero una clara bajada desde el año 1840 hasta 1851. De esta manera, podemos afirmar que, en su etapa más oscura, entre 1835 y 1852, se realizaron sólo 72 mensuras y el DT se dedicó sobre todo a atender algunos casos de delineación urbana en la ciudad de Buenos Aires (Pesoa, 2017, pp. 164-165).

En segundo lugar, podemos intuir que las asignaciones presupuestarias del rosismo tuvieran otros destinos prioritarios, distintos de las tareas topográficas. Prueba de ello son las quejas con respecto a los salarios de los miembros del DT que recoge Martínez Sierra (1975, p. 182). No obstante, no podemos decir que el gobierno de Rosas no estuviera interesado por las labores topográficas. Por ejemplo, en el año 1830 el gobierno le requirió al DT un mapa donde aparecieran cartografiadas las tierras privadas y las tierras públicas. Esto se podría relacionar con el plan que tenía Rosas para el destino de la tierra pública, es decir su enajenación, que pondría fin al sistema enfitéutico rivadaviano (Martínez Sierra, 1975, p. 129). Además, el gobierno requería nuevamente la cartografía para un objetivo que nunca había dejado de estar presente: establecer poblados y fortines y distribuir la tierra para afianzar la población.

Después de la caída de Rosas en Caseros (1852), volvió a entrar en escena el tema del conocimiento del territorio, su organización y registro. La necesidad de una cartografía certera de la provincia seguía siendo un tema acuciante, así como la definición de los límites entre los diferentes partidos y el trazado y localización exacta de los pueblos, además de la necesidad de regulación de los derechos de propiedad sobre las tierras y la definición de estrategias para la expansión de la frontera sobre tierras indígenas. Por estas razones, se decretó en 1852 el restablecimiento del DT. ${ }^{20}$ Canedo (2014) señala que la idea de "restablecimiento" del DT, implicaba resaltar un distanciamiento con respecto al funcionamiento que este había tenido durante el rosismo, pues a pesar de que su actuación había sido escasa, la oficina había permanecido legalmente en funcionamiento.

El decreto de restablecimiento otorgaba al DT la misma organización y funciones que en 1826, marcando una clara continuidad con las ideas rivadavianas sobre sus tareas y su rol en la consolidación estatal. ${ }^{21}$ No obstante, Canedo (2014) señala una diferencia sustancial con respecto a 1826: en aquel momento, la construcción de la agencia estaba anclada en una política sobre tierras públicas, en tanto que en 1852, la situación de tenencia de las tierras había cambiado y el DT se restablecía a la espera de que se construyera un marco legal acorde a la complejidad de la situación. ${ }^{22}$

El catastro era una preocupación prioritaria, tal como expresara el Ing. Carlos Pellegrini en la Revista del Plata, citando a Napoléon: "la primera y la más importante constitución de un pueblo es su catastro" (Pellegrini, 1854, p. 153), para destacar la urgencia que esta labor tenía en ese momento en Buenos Aires. Según Pellegrini, de ello dependía terminar con las querellas provocadas por la incertidumbre en los límites de las propiedades, desarrollar el sistema impositivo (contribución directa), tener conocimiento del territorio para colonización, mejorar la división administrativa y "presentarnos ante el mundo con un documento geográfico que acredite el estado de nuestra civilización, y ostente la variedad y riqueza de un territorio que hace pocos años figuraba en los mapas bajo el chistoso nombre de país del diablo" (Pellegrini, 1854, p. 153).

Desde el gobierno provincial se estableció la necesidad de una sistematización definitiva de los trabajos que dieran cuenta del territorio ocupado. En consecuencia, se le otorgó al DT más integrantes y más presupuesto, incluso con asignaciones extraordinarias, lo que le permitió pasar de una etapa formativa a una etapa de consolidación del quehacer topográfico. De esta manera, la organización propuesta por el decreto de 1852 era la siguiente: presidente (Agustín Ibáñez de Luca),ingeniero 1. ${ }^{\circ}$ (Saturnino Salas),ingeniero 2. ${ }^{\circ}$ (Pedro Pico),secretario (Fermín horma),director de dibujo facultativo (Pedro Benoit), tres oficiales (Nemesio López, Jaime Arrufo, José María Gutiérrez), dos escribientes (Julio Núñez y Octavio Pico) y cuatro delineadores (Pedro Benoit -hijo-, Fabián Pereyra, Antonio Malaver y Juan Fernández). 
Por otra parte, identificamos un cambio en la relación entre el DT y los agrimensores a partir de esta nueva etapa:

...si en la primera época -de 1824 a 1835 - aquellos [los agrimensores] poseían un saber exclusivo sobre el territorio y los órganos estatales dependían de ellos para obtener una visión del país que gobernaban, en la segunda época -de 1852 a $1864-$ la intensidad del control que estableció el departamento sobre los trabajos de agrimensura revela que el Estado tenía ya un volumen de información suficiente como para imponer su criterio y mostrarse más exigente en la materia (Garavaglia y Gautreau, 2011, pp. 15-16).

Por la resolución del 19 de noviembre de 1853 se encargó al DT la determinación de los ejidos de los pueblos de campaña, una tarea que estaba en línea con la estrategia estatal de colonizar el territorio mediante el establecimiento de nuevas poblaciones y que nos indica además que el Estado asume, a través de esta agencia, la tarea de delimitar y organizar el territorio. De acuerdo con los medios con que contaba el DT, se decidió trabajar mediante "Comisiones de Solares", encargadas de arreglar la traza de los pueblos existentes cuyo estado era bastante primitivo e irregular. Para arreglar esta traza era necesario determinar la superficie del ejido, las manzanas, quintas y chacras, medirlas, trazarlas en el plano y amojonarlas en el terreno. ${ }^{23}$

Una nueva etapa comenzó para el DT con la creación del Departamento de Ingenieros (DI) en $1875 .^{24}$ Como hemos visto, el DT había acumulado entre 1852 y 1875 una enorme cantidad de tareas además de la mensura de tierras - tales como el trazado de pueblos nuevos y ejidos, reorganización de los existentes, trazado de caminos, tribunal, acreditación de agrimensores, entre otras- y además había asumido algunas funciones de otras oficinas suprimidas -como la oficina de obras públicas o la de patentes industriales-. D'Agostino (2015) agrega quelas memorias elevadas a las autoridades provinciales en los años previos a 1875 comprueban que la institución estaba recargada de tareas. Ante esta situación, tal como explican D’Agostino y Banzato (2015), las alternativas eran dos: crear un DI que funcionara en paralelo al DT, o bien fusionarlos. La decisión final tomó esta segunda vía, bajo la premisa de que la topografía constituía una rama dentro de la ingeniería.

Esto no es un detalle menor, si tenemos en cuenta que la agrimensura como rama de conocimiento había sido la promotora de una repartición como el DT y que ahora pasaba a ocupar un lugar más entre otras ramas de una ciencia madre que era la ingeniería. Sobre este precepto podemos entender la organización interna del DI, que dividió sus incumbencias en cuatro oficinas específicas: Catastro, Geodesia, Obras Públicas y Puentes y Caminos. ${ }^{25}$ Todas las funciones que había concentrado el antiguo DT se encontrarán, al menos en lo formal, divididas en estos cuatro grupos, en tanto que el catastro y la geodesia se conformarán como dos oficinas separadas que, sin embargo, seguirían teniendo gran importancia en el organigrama del DI y en la práctica, pues aún quedaba bastante territorio por explorar y cartografiar en la Provincia persiguiendo antiguos y nuevos objetivos: a los ya tradicionales objetivos de población y defensa, se sumaría la necesidad de dotar de infraestructuras al territorio provincial.

Diez años después, en 1885, se creó el Ministerio de Obras Públicas de la Provincia de Buenos Aires (MOPBA), varios años antes que su par nacional, creado en $1898 .{ }^{26}$ Con la llamada "Conquista del Desierto" había finalizado la ocupación de las tierras del Oeste bonaerense, hasta el meridiano $\mathrm{V}$, con lo que la provincia había aumentado considerablemente su tamaño. No obstante, y en paralelo, la federalización de Buenos Aires en 1880 había comportado una disminución de poder por la pérdida de la capital, con loque la provincia se enfrentaba al desafío de reestructurarse y cambiar las redes de poder hasta el momento establecidas. Como señala Fernández (2019), el Estado provincial necesitaba expandirse y hacerse presente en los nuevos territorios, a la vez que debió compensar la debilidad causada por el desplazamiento de la centralidad política, económica y cultural. 
FIGURA 3

Organigrama de la posición del DT dentro de la organización del gobierno a partir de 1885

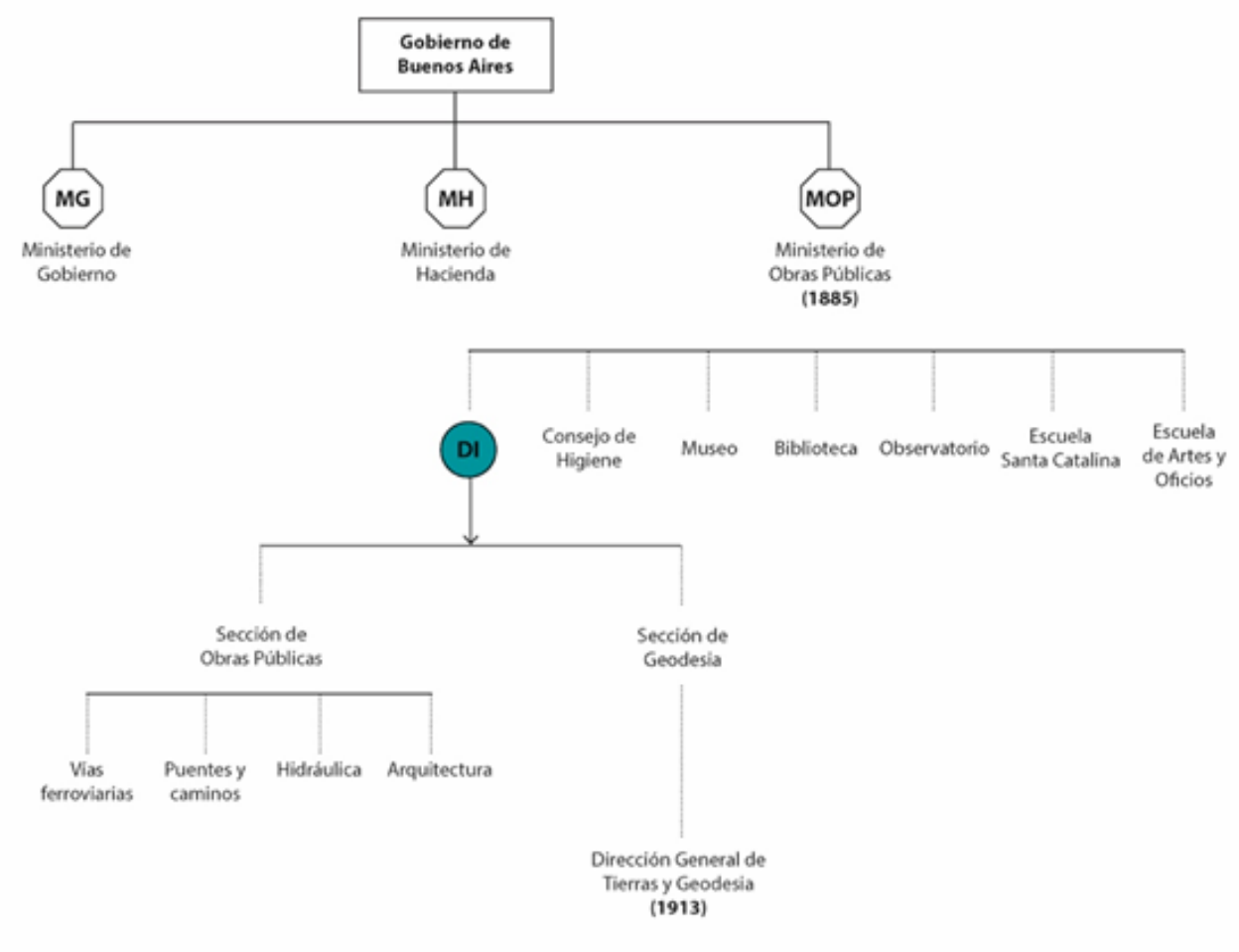

Fuente: elaboración propia.

A partir de este momento, el DI quedó bajo la órbita del MOPBA, que asumió sus funciones, pero reorganizándolas de manera que las oficinas concentraran tareas y saberes aún más específicos. ${ }^{27}$ Dentro del DI se estableció una Sección de Geodesia, encargada de las operaciones geodésicas y topográficas de la provincia y del catastro, lo que incluía realizar planos catastrales de la provincia tales como el Registro Gráfico de las propiedades rurales, la atención a las mensuras y su archivo. Además, siguió bajo su cargo el trazado de los pueblos y la validación de los títulos de agrimensor. ${ }^{28}$

Esta reorganización de las labores, acaecida en apenas diez años, fue posible porque la estructura burocrática de la provincia había adquirido un mayor grado de organización y tenía, por supuesto, mayor tamaño, es decir más personal y un organigrama más extenso. La novedad será la total separación de las tareas de Geodesia de la sección de obras públicas, donde la complejidad será asumida por esta última, en tanto que Geodesia será simplificada a las tareas de su estricta competencia.

Las preocupaciones habían cambiado. Mientras que al principio de siglo la urgencia era construir una base cartográfica certera sobre la cual generar estrategias de ocupación y producción, a finales del siglo el territorio ya estaba efectivamente ocupado tras la llamada Conquista del Desierto y, por lo tanto, la prioridad era conectar y equipar los nuevos territorios. Comenzaron a producirse nuevas dinámicas urbanas a partir del crecimiento poblacional, se crearon nuevos partidos y nuevas infraestructuras de conexión. Por lo tanto, las labores topográficas pasaron a un plano de menor jerarquía, constituyendo una rama más de las obras públicas, las cualespasarán a ocupar un lugar de centralidad en un territorio donde todo está por hacer.

De esta manera, la figura del ingeniero se fue imponiendo sobre la del agrimensor. Si a principios de siglo los ingenieros escaseaban en la región y el agrimensor había ocupado ese lugar vacante, ya a finales de siglo con la institucionalización de la enseñanza de la ingeniería, ${ }^{29}$ existía un amplio grupo de ingenieros formados en el país, a los que se sumaban los extranjeros, que comportaban una masa crítica suficiente como para hacer frente a una oficina de mayores dimensiones y complejidad que lo que hacía décadas había sido el DT. 
Finalmente, el DI fue suprimido en 1913 y las oficinas que lo integraban pasaron a depender directamente del MOPBA. Además, tal como indica Fernández (2019: p. 177), "cambiaron sus denominaciones: las 'secciones' se transformaron en 'direcciones', ganando así jerarquía y autonomía”.

\section{Superar las Dificultades: Normalización Y ESPECIALIZACióN}

Construir el mapa de la provincia constituyó un reto singular, dada la escasa información con la que se disponía. La memoria de los trabajos efectuados por el DT elevada al Gobierno en 28 de marzo de 1826 nos da una idea clara de la dificultad de esta empresa:

Al emprender sus tareas a principios del año 1825 la Comisión Topográfica no contaba con otros datos fundamentales que la carta de Bauzá, la determinación de longitudes y latitudes de varios pueblos por los encargados de la demarcación de límites en la frontera del Brasil, la carta del río ordenada por el Comodoro Bowles, y los viajes por tierra demarcados por la simple estima de Cerviño al salado, de Zizur a las Salinas, Dalve a la costa occidental del Paraná y Reyes a la Sierra de Tandil, Volcán y la Ventana. Pero por útiles que hayan sido estos trabajos a otros objetos, ellos dejaban sin embargo un alto grado de incertidumbre en las deliberaciones de la Comisión..." (citada en Esteban, 1962, pp. 75-76).

Ante esta falta de información el DT se valió de dos recursos. El primero de ellos fue concentrar toda la información cartográfica de la que disponía el gobierno hasta el momento. El segundo fue algo más complejo y ciertamente novedoso: el DT decidió hacer uso de las mensuras catastrales de los terrenos individuales realizadas por agrimensores privados, aunque bajo aprobación del DT- para construir un mapa topográfico a manera de puzle, por compilación de información ya existente o por adquirir. Este método de trabajo ya ha sido puesto de relieve por Garavaglia y Gautreau (2011) como idóneo para momentos en los que escaseaba el personal, los medios económicos y técnicos. Con este método, los agrimensores privados se sometían al DT, que será el que acabe regulando la profesión y la validez de los trabajos realizados. No obstante, aquí nos interesa subrayar esta metodología como signo claro de que topografía y catastro, dos actividades que en ocasiones van por separado, incluso llevadas a cabo por dos oficinas diferentes, se construyeron de manera conjunta en la región.

La propuesta había sido enunciada al menos desde la década de 1820. El 13 de noviembre de 1822, el ingeniero civil y agrimensor José María Manso presentaba al ministro Rivadavia, del que era colaborador, la idea de usar las mensuras como material para conformar el mapa de la Provincia, formando un mosaico, como mecanismo para afrontar la situación mientras no existieran otros levantamientos. Además, esto ayudaría a crear un registro gráfico de propiedades, más fácil de entender, que diera inicio a una sistematización catastral. Las mensuras eran, pese a su realidad fragmentaria e imperfecta, los únicos elementos que aportaban datos sobre la topografía real de la provincia.

Martínez Sierra (1975, p. 79) apunta que el coronel Pedro Andrés García ya había propuesto esta idea, aunque no estaba basada en la experiencia adquirida, a diferencia de Manso. Esta información se complementaría luego con trabajos de campo, que además recogerían datos estadísticos (población, viviendas, etc.). Manso proponía crear secciones de trabajo marcadas por los accidentes naturales, como ríos o arroyos y pretendía llegar en un principio hasta el Río Salado, cosa que en la época suponía un sustancial avance.

El procedimiento propuesto implicaba una condición que imperará en la labor del DT a lo largo del todo el siglo XIX: la normalización en la ejecución de las prácticas. Si observamos el programa de trabajos para 1825 que presentó al gobierno la CT (citado en Martínez Sierra, 1975, p. 88) tras tres meses de su creación, veremos que la gran mayoría de los 17 artículos que contenía estaban dedicados a tareas de uniformización, centralización y normalización: trazar un meridiano de referencia en la capital, construir un patrón de medidas, redactar instrucciones a los agrimensores, conformar una sala de instrumentos y un depósito de cartas y mapas, recopilar estadísticas, conservar mojones, levantar planos de pueblos y ciudades de la provincia 
así como determinar su latitud y longitud, levantar trigonométricamente el plano de la provincia (apoyado en triangulaciones), el plano del Río de La Plata y efectuar la nivelación de la provincia. ${ }^{30}$

Sobre la base de las competencias que recaían sobre el DT y el programa de trabajos inicial, podemos afirmar que la normalización propuesta tenía básicamente tres ejes: la normalización de la profesión, de las prácticas o procedimientos para efectuar los trabajos, y la de los elementos que servían de referencia a estos procedimientos. Estas prácticas pretendían sustentar sobre bases científicas la construcción de toda la información cartográfica de la provincia.

La normalización de la profesión se basó en controlar y certificar que los profesionales que ejercían la agrimensura tuvieran los conocimientos básicos para hacerlo, por lo que el DT se convirtió en el organismo encargado de acreditar su idoneidad. Esta acreditación, probablemente de las primeras en regular las profesiones en el país, se realizaba tras cumplir ciertos requisitos y superar un examen. Las condiciones fueron variando con el tiempo, pero incluyeron tanto pruebas escritas como ciertos períodos de prácticas con un agrimensor de reconocida experiencia. ${ }^{31}$ La normalización de la profesión implica que el Estado es quien legitima un saber, en tanto que antes ese saber era acreditado por el sólo hecho de poseer el conocimiento. A partir de este momento no sólo habrá que tener los conocimientos, sino también demostrarlos antes el Estado.

La normalización de los procedimientos, como parte de una incipiente "racionalización del Estado", estuvo dada por el dictado de una serie de instrucciones a los agrimensores, que estos debían cumplir en todos sus trabajos. Su cumplimiento implicaba estandarizar procedimientos y minimizar el lugar que le cabría a las decisiones dictadas por el buen saber individual, dando lugar, en cambio, a las prácticas normalizadas, tomadas con bases científicas y racionales, bajando el riesgo de sufrir imprevistos. Pedro Andrés García, en sus memorias entre 1811 y 1821 presentadas al gobierno, ya pedía que los encargados de hacer mensuras se ajustaran a unas ciertas normas. Debemos tener en cuenta que, desde la fundación de Buenos Aires, la práctica de la agrimensura se regía solamente por el buen saber y entender del técnico actuante, muchas veces poco cualificado, lo que había dado lugar a una gran cantidad de errores y pleitos por los límites entre las propiedades.

El cumplimiento de las instrucciones dictadas por el DT permitiría la uniformización de los trabajos y la posibilidad de utilizarlos para conformar el mapa general de la provincia. Las primeras instrucciones se dictaron en 1825, con adiciones en 1827, 1835 y 1839. En 1861, tras la reestructuración del DT, se dictaron nuevas instrucciones a las que se les practicaron adiciones en 1863 , pero que se mantuvieron sin modificaciones hasta $1940 .{ }^{32}$

La normalización de los elementos que servían como referencia a los trabajos de medición incluyó tantola demarcación de líneas de referencia -como la elección del Meridiano cero en la ciudad de Buenos Aires, o la traza del meridiano V como límite con la provincia de La Pampa-como la calibración del instrumental o la unificación del sistema de medidas. Este último aspecto fue una de las cosas que más preocupó al DT, puesto que era la tendencia en gran parte de Occidente, a partir de la creación del Sistema Métrico Decimal tras la Revolución Francesa. El 18 de diciembre de 1835, Senillosa elevó al gobierno la memoria sobre la tarea que se le había encargado acerca de la determinación de las equivalencias entre el sistema de medición local de pesos y medidas y el sistema métrico decimal. Así se determinó que la vara era equivalente a $86,6 \mathrm{~cm}$. No obstante, habrá que esperar hasta 1957 para la sanción de la ley que obligaba a adoptar el sistema métrico decimal de manera oficial, y a 1964 para el decreto que exigía que todos los títulos de propiedad expresasen las medidas en metros. Pese a todo ello, ambos sistemas de medidas siguieron conviviendo hasta finales del siglo XIX.

Las mensuras realizadas (unas 13.155 mensuras producidas entre 1824 y 1913, disponibles en el AHG), junto con los trabajos de campo efectuados por diversos agrimensores e ingenieros en ocasión de las diversas campañas militares realizadas al interior, contribuyeron a ampliar y registrar los conocimientos sobre las nuevas regiones que se pretendía incorporar a la provincia. Con estos datos, como hemos adelantado, se construyeron a modo de puzle los sucesivos Registros Gráficos de la Provincia. Estos planos, de enormes 
dimensiones, se editaron en 1830, 1833, 1853, 1855, 1864 y 1890, según consta en el Archivo Histórico de Geodesia (AHG), donde se conservan.

El Registro Gráfico de 1830 es la primera compilación gráfica de los conocimientos acumulados en los 6 primeros años de existencia del DT. Se consignan en esta carta los terrenos de propiedad particular, aquellos entregados en enfiteusis, terrenos no medidos, así como aquellos terrenos cuyas mensuras no han sido registradas en el DT, los ejidos de los pueblos, y se apuntan también las "incoherencias que han resultado en la construcción por las mensuras de los agrimensores".

Sabemos que el DT intenta mantener actualizado este registro, y así en 1833 publica una versión más ajustada. De esta versión tenemos información que nos aporta una carta a Manuel José García, Ministro de Hacienda, de $1833,{ }^{33}$ donde aparecen algunas precisiones hasta ahora inéditas en cuanto a la producción de este documento, que nos confirma que la carta fue efectuada con la mezcla de material de diversas fuentes y fechas. En ella, el DT expresa además una cantidad de dudas con respecto a algunos puntos que tardará aún mucho tiempo en despejar. Por ello deja en manos de la casa Arrowsmith de Londres --a quien se encarga las copias-- corregir la carta con "materiales marinos más auténticos y decisivos", teniendo en cuenta que "los procederes de las mensuras no son del todo evidentes, no sólo por los métodos hasta hoy empleados, sino por los abusos clandestinos a que deben inducir los intereses de los particulares".

FIGURA 4

Registro Gráfico de las Propiedades Rurales, año 1830

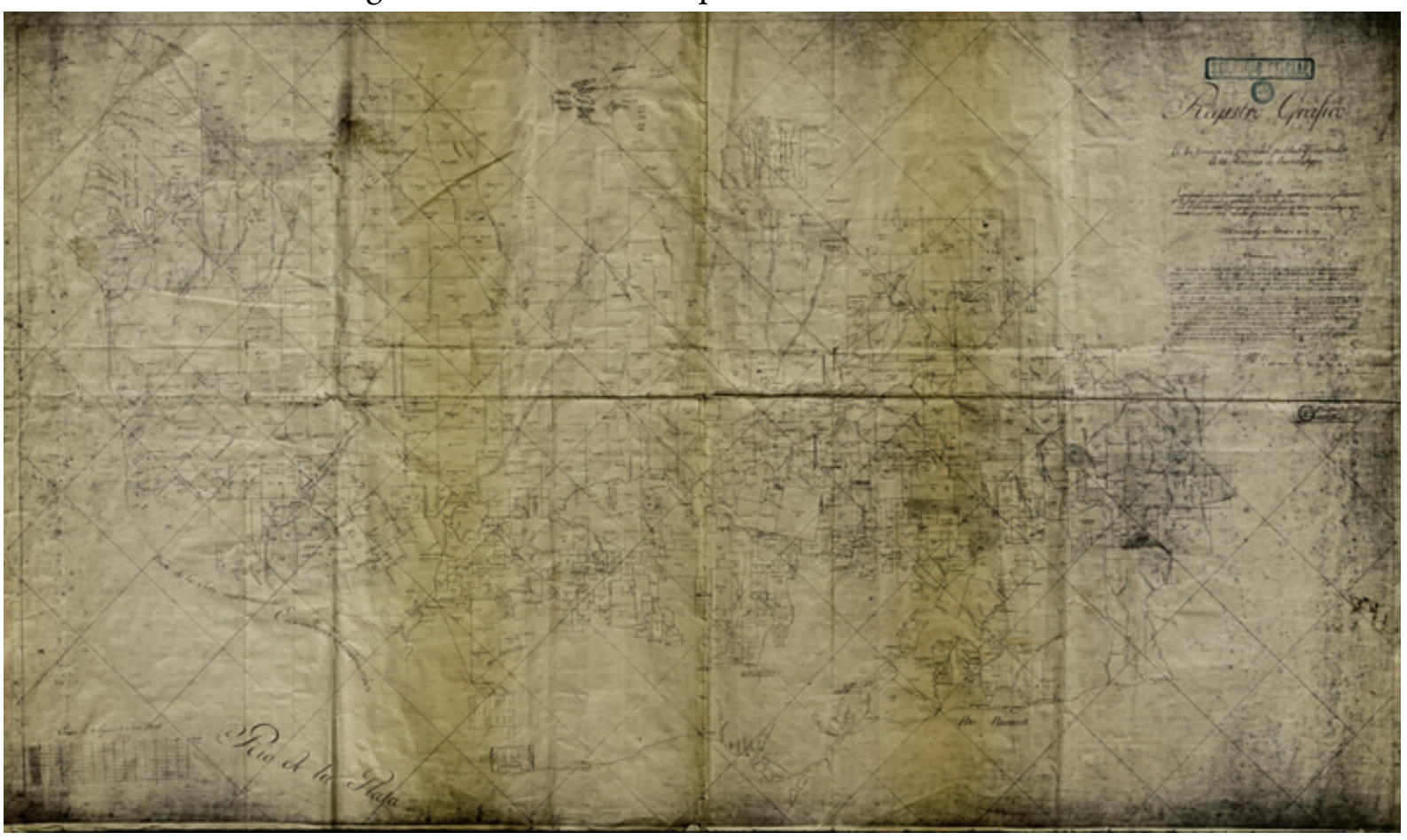

Escala aproximada: 1:440.000. Medidas originales: $1,60 \times 1,00 \mathrm{~m}$

Fuente: AGN.

En la misma carta, se explica claramente el modo en que estaba construido ese registro y la razón por la cual podía haber pequeños errores:

Si se hallase alguna diferencia de longitud y latitud acerca de algunos puntos marítimos o terrestres, con respecto a las observaciones de que hay constancia anterior, esto proviene de que según el método empleado por el Departamento (para la verificación de las mensuras) esta carta se construye sobre una superficie indefinida, y todos los puntos se determinan unos con respecto a otros, según el encadenamiento de las operaciones parciales y con arreglo a una escala lineal de varas y a los rumbos que constan de las diligencias. Después de hecho todo hemos desarrollado la proyección de Mercator arrancando 
de un punto conocido y fijo como es Buenos Aires. Así pues, esta proyección después de ejecutada nos sirve de regla para verificar hasta qué punto hay correspondencia o exactitud en los puntos ya observados entre la proyección geográfica y el desarrollo geométrico. Nos es satisfactorio descubrir que en general hay diferencias muy poco sensibles.

En otras palabras, un territorio hasta entonces desconocido logra un lugar en el mapa gracias a la utilización de una grilla geométrica abstracta, que permite ubicar las piezas sueltas de un puzle en base a puntos determinados. Esta forma de incorporar el territorio al espacio a gobernar mediante el uso de la abstracción geométrica se hacía eco de la que se estaba empleando en aquel momento en muchos lugares del mundo. ${ }^{34}$

Un gran avance en la cartografía bonaerense lo constituye el Registro Gráfico de 1864, que supone un salto de envergadura en el conocimiento del territorio, así como en la forma de representarlo: la costa aparece contorneada con mucho más detalle, así como los elementos naturales (arroyos y lagunas y parte de los sistemas serranos) y los poblados. El nivel de detalle en la zona cercana a la capital es muy alto --teniendo en cuenta que en el RG 1830 esta zona aparecía en blanco-y permite observar claramente la estructura parcelaria en torno al sistema de arroyos. Una carta de 1866en la que el DT escribe a Juan María Gutiérrez, presidente de la comisión nombrada para preparar los objetos que deben enviarse a la Exposición Universal de París de 1867, da algunas precisiones sobre su construcción:

No habiendo hecho jamás trabajos geodésicos que comprendan la provincia toda, ni una parte considerable de ella, los datos con que el RG ha sido construido son las copias que conserva esta oficina de todas las mensuras efectuadas durante 40 años de los terrenos de propiedad particular y pública con datos corregidos por casi todos los agrimensores que han trabajados desde la instalación del DT, en lo que se ve la mucha progresión de adelanto que en método e instrumentos se ha conseguido desde entonces; y en la necesidad de concordar y unir esos trabajos, no debe extrañarse que el "Registro Gráfico" tenga algunos errores. $^{35}$

FIGURA 5

Registro Gráfico de las propiedades rurales de la Provincia de Buenos Aires, 1864

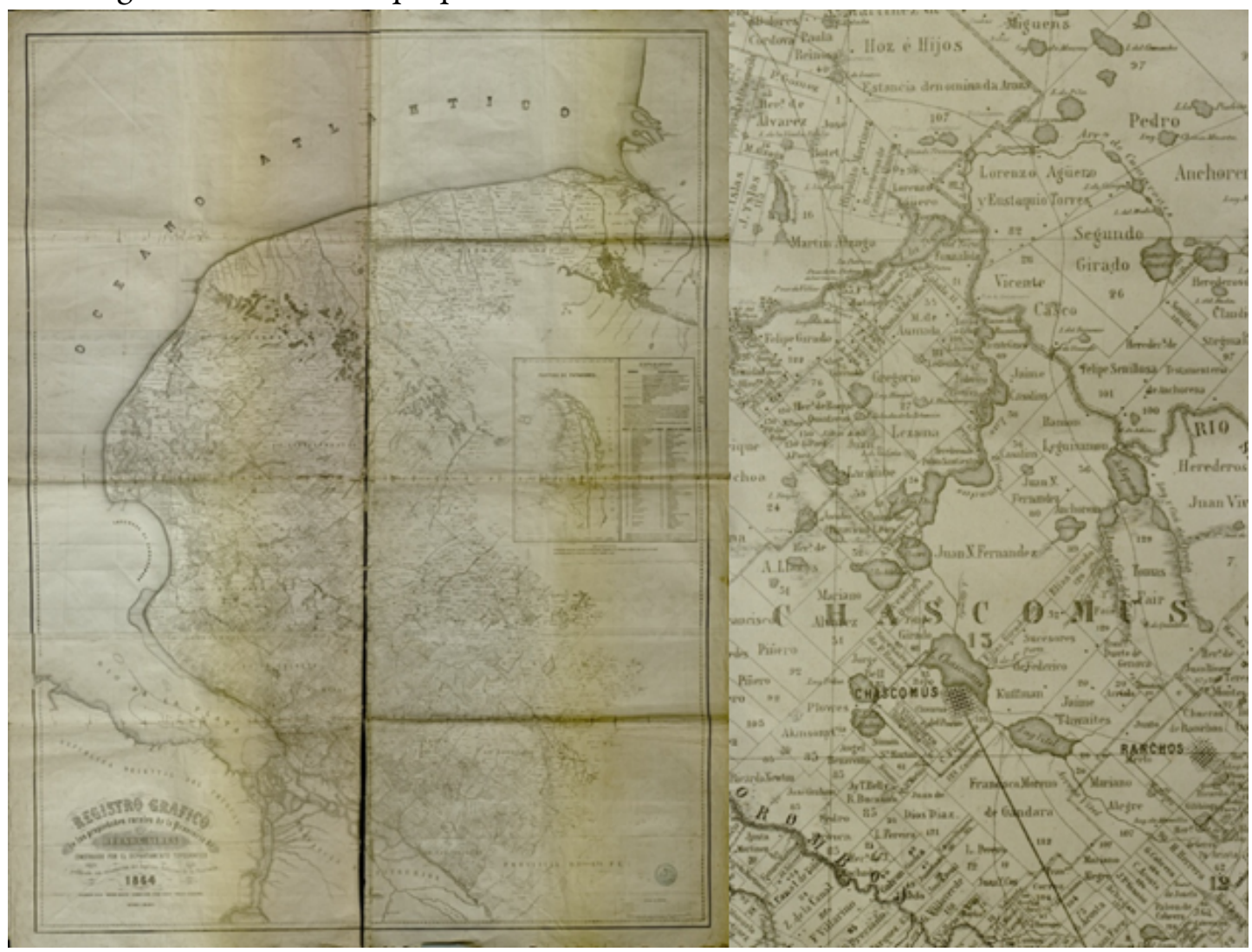

Original y detalle. Medidas originales: $145 \times 188 \mathrm{~cm}$ Fuente: AGN 
Por estas cartas, sabemos también que los ejemplares circulaban por las instituciones científicas del país y del extranjero. ${ }^{36}$ Y la llegada del Registro de 1864 a Europa, le valdrá una medalla de plata en la Exposición Universal de París de 1868, lo que demuestra que la cantidad y calidad del trabajo efectuado por el DT también era valorada en el contexto internacional.

El Registro Gráfico de 1890 supondrá la obra cartográfica catastral general más acabada del DT. Este registro es de singular importancia porque en él se consignan en cada parcela los números de las mensuras que sirven para su ejecución, lo cual ayuda a identificar los antecedentes de cada terreno, aún en la actualidad. Estaba construido, como los anteriores, en base a la compilación de todas las mensuras individuales, pero en este caso se elaboraron, además del mapa general, hojas para cada partido que facilitarían su consulta y manejo.

A pesar de lo certero de este mapa, es preciso aclarar que no se realizó sobre una base de triangulación geodésica. La triangulación general del territorio provincial y nacional comenzará en 1906, como una incumbencia del Instituto Geográfico Militar (IGM). ${ }^{37}$ Y aún habrá que esperar hasta 1941 (Ley de la Carta) para comenzar trabajos geodésicos sistemáticos y regulares a nivel nacional a cargo de esta institución.

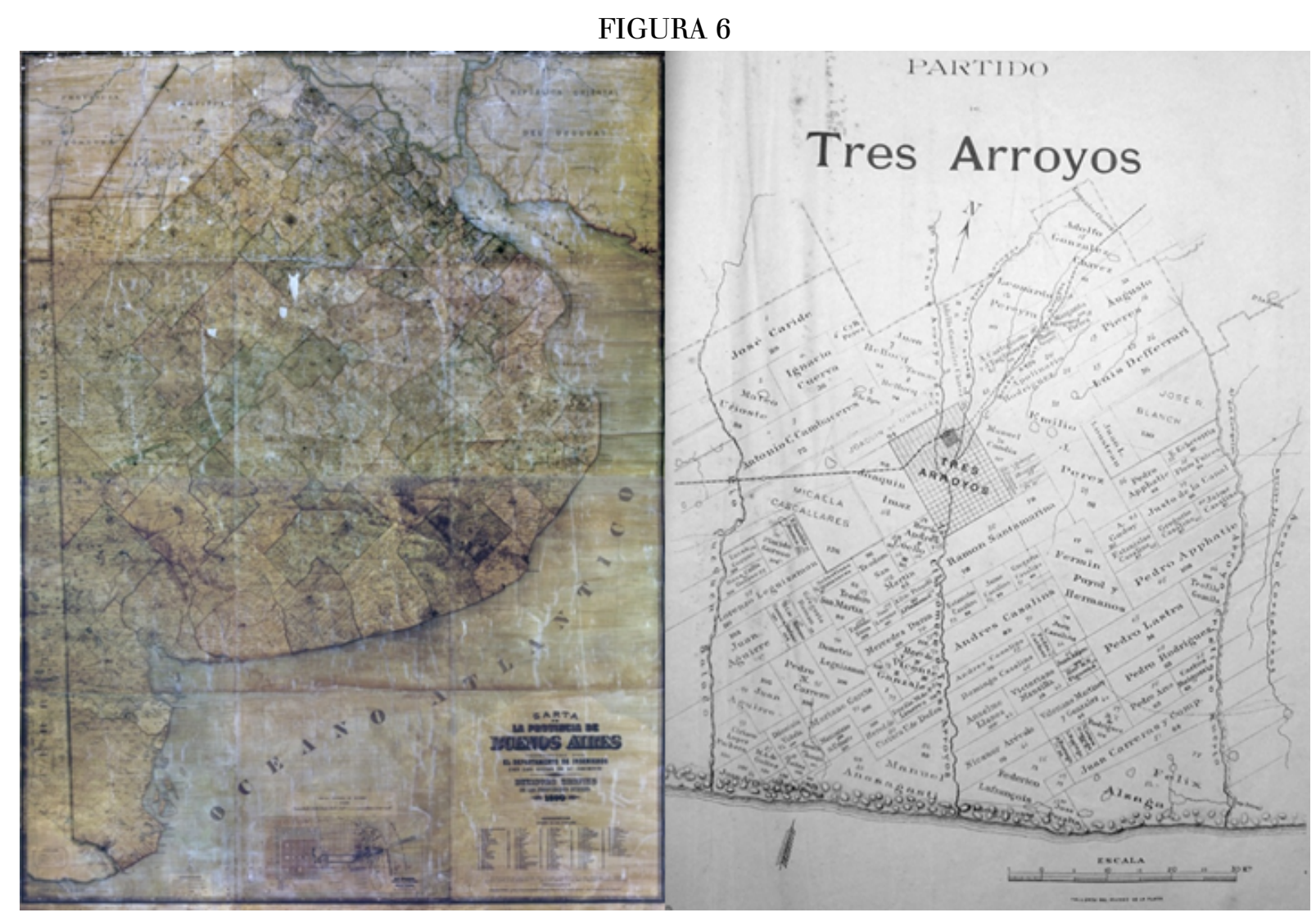

Izquierda: Registro Gráfico de las propiedades rurales de la Provincia de Buenos Aires, 1890. Medidas originales: 231 x $173 \mathrm{~cm}$. Derecha: Detalle de una de las hojas construidas por partido Fuente: Biblioteca Nacional Argentina / AHG.

\section{Conclusiones}

A lo largo del presente texto hemos intentado poner en valor la actividad del DT a lo largo de casi un siglo, una institución clave en el proceso de formación del Estado provincial, pues fue la encargada de definir el territorio que se pretendía gobernar. Con el correr de los años, el DT pasó a ocupar un rol ciertamente periférico dentro del Estado si se lo compara con el que tuvo en sus orígenes. La razón de ello 
reside en que para la década de 1910 toda la tierra de la Provincia de Buenos Aires había sido ya incorporada a la producción (sobre todo agrícola-ganadera) y surgieron nuevas problemáticas para resolver. Es así que la creación del DI a finales del siglo XIX supuso la fusión de algunas reparticiones con más trayectoria histórica con otras más modernas, surgidas para enfrentar problemas que ya no tenían que ver con colonizar sino más con conectar y equipar.

El análisis de la trayectoria del DT nos ha permitido, además, evidenciar la construcción del catastro a nivel provincial. Su carácter pionero, como la primera institución catastral de América Latina, le convirtió en un referente para las otras provincias del país y para otros países de la región. En un contexto de ocupación de nuevas tierras, muchas de ellas desconocidas hasta el momento, la presencia de los agrimensores e ingenieros fue muchas veces la referencia del poder estatal en estos territorios de nueva ocupación.

Pero el mapa que se fue construyendo poco a poco, hasta alcanzar su versión más acabada en 1890, no sólo servía a propósitos catastrales, sino que aportaba además información crucial para definir estrategias políticas, económicas y sociales. En este sentido, la búsqueda por definir y mejorar esa cartografía que llevó varias décadas puede ser vista como una continuidad subyacente a los vaivenes institucionales.

La investigación nos ha permitido destacar un rasgo fundamental de la producción cartográfica en los inicios del periodo independiente, y es la íntima relación entre catastro y topográfica, dos ramas que se irán separando poco a poco hasta su total diferenciación a cargo de agencias separadas. En el caso bonaerense, las construcciones del mapa catastral y del mapa topográfico fueron de la mano durante casi todo el transcurso del siglo XIX. La escasez de medios y de personal obligóa la unión de esfuerzos desde el principio y las tareas fueron racionalizadas a partir de la normalización de la profesión, de los procedimientos para efectuar los trabajos y de los elementos que servían de referencia a estos procedimientos. Esto permitió alcanzar un grado de conocimiento del territorio bastante significativo en un corto tiempo. Sobre la base de este mapa (o mapas), la región podía mostrarse al exterior como atractiva para su colonización y para invertir en ella.

Por último, y más allá de este uso operativo de la cartografía, es preciso destacar que el caso del DT nos permite observar una concentración cada vez más marcada de funciones en manos del Estado y, más específicamente, de saberes. Concentrar estos saberes fue crucial para la construcción del Estado provincial, pues el saber técnico permitió decidir políticas económicas, definir políticas de colonización e incluso estrategias militares, así como establecer métodos de conexión, proyectos de infraestructuras, decidir la forma, límites y ubicación de las unidades territoriales que conformaban la provincia, así como la ubicación de los diferentes núcleos de población. Todas estas medidas, esenciales para la construcción y consolidación del Estado, hubiesen sido imposibles sin una base cartográfica que les diera sustento.

\section{ReFERENCIAS}

Aliata, F. (2006). La Ciudad Regular: Arquitectura, Programas e instituciones en el Buenos Aires posrevolucionario, 1821-1835. Bernal (Argentina): Universidad Nacional de Quilmes/Buenos Aires: Prometeo.

Aliata, F. y Loyola, O. (2005). La acción del Departamento Topográfico y las Comisiones de Solares en la consolidación de los poblados bonaerenses. Dolores entre 1821 y 1838. En Batticuore, G., Gallo, K. y Myers, J. Resonancias románticas. Ensayos sobre historia de la cultura argentina (1820-1890). Buenos Aires: Eudeba.

Asúa, M. de (2010). La ciencia de Mayo: Cultura cientifica en el Río de La Plata, 1800-1820. Buenos Aires: Fondo de Cultura Económica.

Bohoslavsky, E. y Soprano, G. (2010). Un estado con rostro humano. Funcionarios e instituciones estatales en Argentina (desde 1880 a la actualidad). Buenos Aires: UNGS / Prometeo.

Canedo, M. (2013). Cartas entre agrimensores. Miradas desde los pueblos en un período de transiciones políticas, institucionales y sociales (Estado de Buenos Aires, 1854-1856). Revista Electrónica de Fuentes y Archivos, 4(4), 209-222. Córdoba, Centro de Estudios Históricos Prof. Carlos S. A. Segreti. 
Canedo, M. (2014). El “restablecimiento" del Departamento Topográfico de Buenos Aires. Política y gestión de un proyecto con consenso (1852-1857). Andes, 25(2).

Craib, R. (2013). México cartográfico: Una historia de limites fijos y paisajes fugitivos. México: UNAM.

Chiaramonte, J.C. (1997). Ciudades, provincias, Estados: Orígenes de la Nación argentina (1800-1846). Buenos Aires: Ariel.

D’Agostino, V. (2007). Los orígenes de la agrimensura como profesión: su relación con el Estado y el régimen de propiedad de la tierra (Provincia de Buenos Aires, primera mitad del siglo XIX). En N. Girbal y S. N. de Mendonça (coord.), Cuestiones agrarias en Argentina y Brasil: Conflictos sociales, educación y medio ambiente (pp. 271-288). Buenos Aires: Prometeo.

D’Agostino, V. (2015). Estado, instituciones y funcionarios bonaerenses: la reorganización de la repartición topográfica en la segunda mitad del siglo XIX. En M. Blanco y L. Barandiarán (comps.), Las configuraciones de la trama social. Políticas públicas, instituciones y actores en la Argentina contemporánea (pp. 14-42). Tandil: Universidad Nacional del Centro de la Provincia de Buenos Aires.

D’Agostino, V. y Banzato, G. (2015). Funcionarios y políticas sobre el territorio en la Provincia de Buenos Aires: El Departamento de Ingenieros, 1875-1913. Recuperado de http://www.memoria.fahce.unlp.edu.ar/trab_evento s/ev.4113/ev.4113.pdf.

Esteban, F. (1962). El Departamento Topográfico de la Provincia de Buenos Aires (actual dirección de Geodesia). Su creación y desarrollo. Antecedentes y documentos demostrativos de la importancia de sus funciones. Breve reseña para su historia. Buenos Aires: Dirección de Geodesia.

Fernández, N. (2019). Agencias estatales, política y burocracia técnica: el Ministerio de Obras Públicas de la Provincia de Buenos Aires, 1917-1943. Estudios sociales del Estado, 5(10), 168-208.

Garavaglia, J.C. y Gautreau, P. (2011). Mensurar la tierra, controlar el territorio: América Latina, siglos XVIII-XIX. Rosario: Prohistoria.

Gelman, J. (ed.) (1997). Un funcionario en busca de un Estado: Pedro Andrés García y la cuestión agraria bonaerense, 1810-1822. Buenos Aires: Universidad Nacional de Quilmes.

Kain, R. \& Baigent, E. (1992). The Cadastral Map in the Service of the State. A History of Property Mapping. Chicago: University of Chicago Press.

Martínez Sierra, R. (1975). El mapa de las pampas, tomo II. Buenos Aires: Dirección Nacional de Registro Oficial.

Nicolau, J.C. (2005). Ciencia y técnica en Buenos Aires, 1800-1860. Buenos Aires: Eudeba.

Oszlak, O. (1982). La formación del Estado argentino: orden, progreso y organización nacional. Buenos Aires: Planeta.

Pellegrini, Ch. (1854). Organización de un cuerpo de Ingenieros Geógrafos para el Estado de Buenos Aires, algún día adaptable a las demás provincias de la confederación. Revista del Plata, 11, 153-155.

Pesoa, M. (2017). Conocer, medir y dibujar el territorio. Orígenes y etapa formativa del Departamento Topogra\#fico de Buenos Aires (1824-1851). Boletin Americanista, 75, 153-172.

Plotkin, M. y Zimmermann, E. (comp.) (2012). Los Saberes del Estado. Buenos Aires: Edhasa.

Sábato, H. (2013). Ensayo introductorio. Buenos Aires de 1820 a 1880: procesos, actores, conflictos. En M. Ternavasio (dir.), Historia de la provincia de Buenos Aires, tomo 3 (pp. 15-46). Buenos Aires: Unipe-Edhasa.

Schlögel, K. (2007). En el espacio leemos el tiempo: Sobre historia de la civilización y geopolítica. Madrid: Siruela.

\section{Notas}

1 Antes de la creación del DT, las tareas de mensura de tierras o elaboración de mapas topográficos estaban a cargo de un escaso número de profesionales relacionados con la ingeniería militar, las matemáticas, la cosmografía y la navegación marítima (estos últimos, los pilotos, conocían cómousar la brújula y por tanto colaboraban en mediciones terrestres). Asimismo, muchas mediciones fueron efectuadas por personajes con escasos conocimientos sobre el tema, redundando en una acumulación histórica de errores topográficos. La escasez de profesionales idóneos queda de manifiesto en los constantes esfuerzos que realizan Manuel Belgrano y otros personajes de la época por consolidar la enseñanza de las matemáticas y el dibujo, entre otras ciencias, desde la última década del siglo XVIII. 
2 Con este dinero se pretendía construir el puerto de Buenos Aires, dotar de un servicio de agua corriente a la ciudad y fundar pueblos en la frontera y en la costa.

3 Decreto de 4 de septiembre de 1812. Todos los decretos mencionados en este texto pueden consultarse en el Registro Oficial (R.O.).

4 Aliata (2006) habla de la noción de regularidad como concepto que sintetiza la transformación llevada a cabo por la gestión rivadaviana, en el paso de la acción urbana del Antiguo Régimen a la década de 1820. La regularidad se presenta en oposición al desorden y la civilización, creando una rutina predecible. La regularidad no aparece sólo en el ámbito de la arquitectura, la ingeniería o la ciudad, sino que también aparece en el ámbito político y militar, donde una serie de acciones han de ser predecibles y debe haber un uso racional de la fuerza, lo que hace necesario que las actuaciones sean constantemente visibles, observadas por todos. Regularidad también significa ausencia de complejidad o, en otras palabras, claridad en las acciones y en las formas, como resultante formal de la "civilización".

5 Con el objetivo de modernizar diferentes aspectos de gestión, en 1821 el gobierno provincial crea tres ministerios: Gobierno, Hacienda y Guerra. Durante los siete años que está en el gobierno trabaja sobre leyes para el desarrollo de la agricultura, la ganadería y la minería, reformas militares; se reorganiza el servicio de policía, se trabaja sobre medidas para el avance de la frontera contra el indio y la mejora de la mano de obra rural; aumenta el número de escuelas primarias incluyendo a las niñas en el sistema educativo y se modernizan los programas y los métodos, a la vez que se funda la Universidad de Buenos Aires; se sanciona una ley de sufragio universal y se suprimen algunos privilegios coloniales de la iglesia. Debemos destacar, sin embargo, que esta no es una iniciativa exclusiva de Rivadavia, sino de todo un grupo de personas al cuale él mismo pertenece, herederos de la ilustración y de las reformas borbónicas, que siguen las inspiraciones de pensadores liberales como Jeremy Bentham -a quien Rivadavia había conocido personalmente en Londres-, Benjamin Constant o Destutt de Tracy.

6 Además, debemos recordar que la formación de técnicos había sido una preocupación de Manuel Blegrano, algunos años antes, que en 1899 había fundado la Escuela de Náutica, la de Dibujo y, más tarde, la de Matemáticas. La importancia que revestía la cuestión del conocimiento científico sobre el territorio se ve reflejada en una de las primeras medidas tomadas después de la Revolución de Mayo: la reapertura de la Escuela de Matemáticas, bajo la dirección de Felipe de Sentenach. En 1816, el director pasó a ser Felipe Senillosa, y entre sus alumnos estuvieron: Avelino Díaz, José Arenales, Antonio Saubidet, Pedro Bernal y Manuel Chilavert, entre otros.

7 El Departamento de Ingenieros Hidráulicos se crea en 1822 y su jefe será Santiago Bevans. La idea era que el Departamento se hiciese cargo de la dirección del agua de toda la provincia y, especialmente, de establecer un puerto y un sistema de distribución de agua para Buenos Aires. Por lo tanto, fue una institución que demuestra que se le da importancia específica a un tema que desde la ilustración se debatía. No obstante, fue disuelto en 1829.

8 Decreto del 23 de oct de 1821. En 1824 estaba conformado por: 1er. Jefe Pro\#spero Cateli\#n, 2do. Jefe Juan Ponce y Oficiales Auxiliares: Teodoro Schuster y Pedro Benoit (padre).

9 Decreto de 24 de diciembre de 1823.

10 Decreto de 9 de abril de 1824.

11 Decreto de 24 de septiembre de 1824. En el decreto de su establecimiento, la Comisión Topográfica queda conformada por: el editor del Registro Estadístico, el prefecto de ciencias exactas y el catedrático de físico-matemáticas, más dos oficiales auxiliares. Las tres primeras autoridades de la Comisión son Felipe Senillosa, Vicente López y Planes y Avelino Díaz, a las que luego se suman Martiniano Chilavert como primer oficial, Juan Saubidet como segundo escribiente y Agustín Ibáñez de Luca como oficial meritorio.

12 El 16 de noviembre de 1824 la Sala de Representantes sancionó una ley que volvía a determinar la realización de un plano topográfico y asignaba la suma de 100 pesos a esta tarea (Martínez Sierra, 1975, p. 86). Esta medida legislativa, complementaba a la medida gubernamental de creación de la CT, evidenciando la importancia que tenía para el gobierno la elaboración del mapa.

13 Decreto de 24 de septiembre de 1824.

14 Aquí comienza una serie de diferencias entre el DIA y el DT sobre las incumbencias de cada uno. En un decreto de 6 de julio de 1826, se le atribuye al DT el trazado de calles plazas y caminos, atribuciones que antes pertenecían al DIA, exceptuando las mandadas a ejecutar antes de esa fecha.

15 Además, un año después, se creó el archivo de este Departamento para poder reunir la cartografía existente de la época colonial (Decreto de 26 de marzo de 1827).

16 Sábato (2013, p. 27) enumera las principales instituciones creadas bajo la administración rivadaviana, muy influida por el iluminismo y el utilitarismo: “... en materia de organización institucional y política, la puesta en funcionamiento de los poderes del Estado --gobernador y ministros, Sala de Representantes, aparato judicial, supresión de los cabildos--, la reorganización militar, el ordenamiento fiscal y de la hacienda pública, y el dictado y la puesta en vigencia de la ley electoral...".

17 Felipe Senillosa era ingeniero militar en Alcalá de Henares y había participado en el ejército napoleónico. Conoció a Rivadavia, Sarratea y Belgrano en Londres, y accedió a trasladarse para ejercer su profesión en el Rio de La Plata, donde 
ejerció como director de la Academia de Matemáticas y tuvo una activa vida cultural en la ciudad. Senillosa y López y Planes formaban parte de la Sociedad Literaria y se dedicaban a la difusión del saber científico entre los miembros de la élite de la época.

18 Asimismo, durante la década del 20, las pretensiones de centralización desde Buenos Aires hacen que por momentos se plantee que el DT lo sea de todo el territorio nacional.

19 Los primeros agrimensores acreditados, en el año 1826, fueron: Francisco Mesura, José de la Villa, José María Manso, Marcos Chiclana, Carlos Suárez, Francisco Isach, Antonio Simonnin, Magín Roca, Fortunato Lemoine, Joaquín Pareja, Ambrosio Crámer y Teodoro Schuster.

20 Decreto de 26 de junio de 1852.

21 Tras Caseros, el general Urquiza como presidente de la Confederación Argentina, nombra gobernador provisorio de Buenos Aires a Vicente López y Planes (febrero a julio de 1852) y como ministro de Gobierno (1852-1854) a Juan María Gutiérrez -quien más tarde ejercerá de ministro de relaciones exteriores (1854-1856) --. Ambos habían formado parte del DT anteriormente y además Gutiérrez era agrimensor, por lo que hay que destacar el rol destacado que ocuparon estos profesionales en la toma de decisiones en la época. Tal como señala Canedo (2014, p. 28), en todas las decisiones que se tomaron tan expeditivamente a lo largo de 1852 "apareció el impulso del gobierno a través del ministro correspondiente (de Gutiérrez en estas acciones, pero antes de Alsina, y después de Portela), evidenciando una clara intencionalidad política de los gobiernos para lograr el restablecimiento institucional del Departamento.”

22 Asimismo, en el momento de su restablecimiento, se le quita al DT cualquier incumbencia sobre temas estadísticos, que sí estaban contemplados en 1826.

23 Sin embargo, las Comisiones de Solares no eran una novedad. En 3 de febrero de 1827 se había decretado que las Comisiones de Solares serían las encargadas de repartir las suertes de quintas y estancias de los ejidos, según las instrucciones del DT. Pero es en 1854 cuando se ponen finalmente en marcha, aunque su existencia sea relativamente corta.

24 Ley 757 sancionada el 8 de octubre de 1875.

25 El DI se componía de un presidente, cuatro vocales ingenieros civiles y tres vocales agrimensores. Estos tres vocales agrimensores ejecutaban además las funciones de la Sección de Geodesia, bajo la dirección de uno de ellos. Estos agrimensores eran: Carlos Encina, German Kuhr y Edgardo Moreno.

26 Un hecho decisivo en la creación del MOPBA fue la fundación de La Plata y el proceso de reformas institucionales que encara el nuevo Estado provincial.

27 El MOPBA también asumió nuevas funciones relacionadas con agricultura, ganadería, salud pública o asuntos de inmigración y colonización.

28 Esta última competencia se anula en 1897, por existir la Universidad (disposición de 18 de diciembre de 1897).

29 Por iniciativa de Juan Mari\#a Gutiérrez, a la sazón Rector de la Universidad de Buenos Aires, se creó el Departamento de Ciencias Exactas, dentro del cual comenzó a funcionar la carrera de ingeniero en 1866, graduándose los primeros en 1870. Unos años más tarde, en 1897 se fundó la Facultad de Ciencias fisicomatemáticas de la recién creada Universidad Nacional de La Plata. Ese mismo año se iniciaron los cursos, con una matrícula de veinte alumnos regulares. Se expedían los diplomas de ingeniero civil, mecánico, arquitecto, agrimensor, doctor en ciencias físico-matemáticas, doctor en ciencias naturales y doctor en química.

30 Entre otras tareas más proyectuales como proponer trabajos para mejorar el curso de las aguas de la provincia, proyectar una red de caminos o atender a la futura navegación interior de la provincia (algo cuya posibilidad aún no se había comprobado).

31 Esta validación se anuló en 1897 cuando comenzó a impartirse la carrera en la universidad.

32 El texto de las mencionadas instrucciones y sus adiciones puede encontrarse compilado en la publicación de las Instrucciones a los Agrimensores de 1940 que en 1945 realizó el MOPBA.

33 AHG, correspondencia caja 1, carta n. ${ }^{\circ} 117,6$ de agosto de 1833.

34 La abstracción geométrica sirvió tanto para medir y cartografiar como para efectuar repartos de tierras más fácilmente. Muy conocidos son los casos del mapa topográfico de Francia -efectuado por la dinastía Cassini entre los siglos XVII y XVIII- y del mapa de Jefferson de 1783 -que sirvió de base para la subdivisión de las tierras al Oeste del río Ohio-. Más allá de estos ejemplos, podemos citar también el uso de la abstracción geométrica en la consolidación de la ocupación imperial, como es el caso de la medición del subcontinente indio expresada en el Great Trigonometrical Survey. Según Schlögel (2007, p. 190) este mapa es la expresión más completa del "ideal de la ilustración europea, medir y captar el mundo en un proceso empíricamente exacto y racionalmente controlado”.

35 Carta de 27 de enero de 1866 (AHG, correspondencia caja 2, carta n.257).

36 AHG, Carta n. ${ }^{\circ} 274$, caja 2, 3 de abril de 1868 a J. M. Gutiérrez, Rector de la Universidad: Se adjuntan 20 ejemplares del RG para que lo distribuya "entre las corporaciones, establecimientos o personas competentes de Europa y América que V. E. Juzgue conveniente", con el objetivo de dar a conocer el trabajo y el territorio. 
37 El IGM tiene origen en la Oficina Topográfica Militar creada en 1879 a fin de prestar servicios a la Expedición del Desierto del Gral. Roca (ministro de Guerra del presidente Avellaneda). Al frente de la oficina estaba inicialmente el Teniente Coronel Manuel Olascoaga, encargado de la realización del mapa topográfico de la llamada "Conquista del Desierto”. En 1901 esta oficina pasa a llamarse Instituto Geográfico Militar y en 1919 se le otorga la responsabilidad de la elaboración de la cartografía oficial del país. En 2009 pasa al ámbito civil bajo el nombre de Instituto Geográfico Nacional. 